\title{
Safety and Accuracy of the Freehand Placement of C7 Pedicle Screws in Cervical and Cervicothoracic Constructs
}

\author{
William Clifton ${ }^{1}$, Christopher Louie ${ }^{2,3}$, David B. Williams ${ }^{4}, 5$, Aaron Damon ${ }^{1}$, Conrad Dove \\ ${ }^{6}$, Mark Pichelmann ${ }^{1}$ \\ 1. Neurological Surgery, Mayo Clinic, Jacksonville, USA 2. Neurosurgery, Mayo Clinic, Jacksonville, USA \\ 3. Neurosurgery, Dartmouth Hitchcock Medical Center, Lebanon, USA 4. Aviation Medicine, Marine \\ Corps Air Station Beaufort, Beaufort, USA 5. Internal Medicine, Marine Corps Air Station Beaufort, \\ Beaufort, USA 6. Neurosurgery, Mayo Clinic, Rochester, USA
}

Corresponding author: William Clifton, clifton.william@mayo.edu

\section{Abstract}

Background: Cervical pedicle screws are advantageous in their biomechanical stability within cervical and cervicothoracic constructs. The seventh cervical vertebra contains relatively large pedicles and has a low incidence of vertebral artery localization within the transverse foramina. The freehand technique of pedicle screw insertion is advantageous in decreasing intraoperative radiation exposure both to the patient and surgeon. In this study, we investigated the safety and accuracy of $\mathrm{C} 7$ pedicle screw placement at our institution utilizing an anatomic freehand technique.

Methods and Materials: A retrospective study was performed, and 20 patients were identified who met the inclusion criteria over a five-year period (2013-2018). The C7 pedicle screw placement capability and accuracy were recorded. Accuracy was graded based upon postoperative imaging on a Grade $0-3$ scale for breach assessment. Any neurologic complications related to screw placement were also recorded.

Results: Successful pedicle screw placement occurred in 90\% of attempts (36/40). The overall screw accuracy rate was 89\% (32/36). There were four minor breaches (Grade 1) identified on CT, without neurologic complications. The fusion rate in our cohort for patients with follow up greater than eight months was $100 \%$.

Conclusions: In our patient series, the freehand technique of $\mathrm{C} 7$ pedicle screw placement utilizing a small laminotomy with direct pedicle palpation appears to be a safe and accurate method for screw placement, and provides adequate biomechanical stability for cervical and cervicothoracic construct fusion.

Received 07/25/2019

Review began $07 / 28 / 2019$

Review ended 07/31/2019

Published 08/02/2019

CC Copyright 2019

Clifton et al. This is an open access article distributed under the terms of the Creative Commons Attribution License CC-BY 3.0., which permits unrestricted use, distribution, and reproduction in any medium, provided the original author and source are credited.
Categories: Neurosurgery, Orthopedics

Keywords: cervical pedicle screw, freehand, vertebral artery, spinal instrumentation, cervical fusion

\section{Introduction}

Fixation options for the subaxial cervical vertebrae include lateral mass, translaminar, transfacet, and pedicle screws [1]. Pedicle screw placement is biomechanically advantageous due to increased pullout strength of instrumentation [2]. The location of the vertebral artery with respect to the pedicle in the subaxial cervical spine poses a challenge for screw 
placement [3-4]. At C7, however, the vertebral artery enters the transverse foramen for a small percentage of the time (10\%-15\%), and thus placement of a pedicle screw at this level poses less of a risk to arterial injury [5]. There are multiple techniques for the placement of $\mathrm{C} 7$ pedicle screws, including freehand, CT-guided navigation, and fluoroscopic guidance [6]. The freehand method decreases intraoperative radiation exposure and operative times, however, requires technical acumen and detailed anatomical knowledge of the cervicothoracic junction [7-8]. Familiarity with the freehand method for $\mathrm{C} 7$ pedicle instrumentation is an important technique to possess in the surgeon's armamentarium in the case of navigation equipment failure or incorrect registration. This technique can be guided by direct pedicle palpation through a small laminotomy at the superior aspect of the C7 lamina [9-10]. At our institution we have employed this technique for $\mathrm{C} 7$ pedicle screw placement fixation at the cervicothoracic junction. This study aimed to quantify the safety and viability of freehand pedicle screw placement at C7 using this method.

\section{Materials And Methods}

With IRB approval, a retrospective review was conducted by two independent reviewers (WC, CL) of all patients undergoing cervical or cervicothoracic fusion by a single surgeon (senior author) at our institution and it was performed over a five-year period (2013-2018). Our inclusion criteria for the study were: adult patients (18 years or older) undergoing posterior cervical or cervicothoracic fusion for any indication that included the $\mathrm{C} 7$ level using freehand technique and postoperative X-ray or CT, and any intraoperative attempt to place $\mathrm{C} 7$ pedicle screws. Exclusion criteria were patients with previous $\mathrm{C} 7$ instrumentation undergoing revision surgery, patients who did not have an intraoperative attempt at $\mathrm{C} 7$ pedicle screw placement, and instrumentation using navigation or intraoperative fluoroscopy during screw placement.

Primary outcomes were C7 screw placement capacity, accuracy, and any neurologic complications related to screw placement. Secondary outcome measurement was fusion rates for patients with at least eight months of follow up. Fusion was defined as bony bridging between adjacent vertebral segments throughout the entirety of the construct identified on CT or plain film. Accuracy was graded for patients by analysis of postoperative X-ray or CT. For patients with a postoperative CT, accuracy was graded upon previously published scales [11]: for patients with a postoperative plain film, breach rates were identified based upon a previously published method shown to have high sensitivity and specificity for pedicle screw breaches compared with CT [12]. Demographics recorded included patient age, surgery performed, size and length of $\mathrm{C} 7$ screws used, and location of the instrumented $\mathrm{C} 7$ level in the fusion construct (bottom or middle). Any identifiable intraoperative breaches requiring screw revision at the time of placement or new postoperative neurologic deficits were also recorded. Postoperative imaging modalities to confirm screw placement were recorded.

Details of the utilized operative technique for freehand C7 pedicle screw placement are as follows. A preoperative MRI is obtained on all preoperative patients for surgical planning. The vertebral artery can be easily identified on $\mathrm{T} 2$ sequences to determine its course in relation to the $\mathrm{C} 7$ pedicle. If a transverse foramen exists at $\mathrm{C} 7$ and includes the vertebral artery, then pedicle screws are not placed to avoid neurovascular complications. After complete exposure of the posterior elements of the levels desired to be instrumented, the $\mathrm{C} 7$ lateral mass is identified. If the construct is planned to cross the cervicothoracic junction, the thoracic screws are placed first. This aids in starting point planning for the $\mathrm{C} 7$ pedicle screw in order to successfully place the rod into the polyaxial heads across the junction. After the thoracic screws are placed, a small laminotomy is performed at the superior border of the $\mathrm{C} 7$ lamina (see Figure 1). The pedicle can then be directly palpated. The superior and inferior borders are identified, which provides the cranial-caudal trajectory in order to avoid breaches into the superior or inferior foramen. The medial-lateral trajectory can then be planned based upon the directly palpated medial border of the $\mathrm{C} 7$ pedicle, as well as the previously placed thoracic 


\section{Cureus}

pedicle screw. The starting point is created by a high-speed burr through the posterior cortex. The pedicle is then accessed with a handheld power drill. The drill is initially set to $20 \mathrm{~mm}$, and then can be increased in $2 \mathrm{~mm}$ increments until the anterior cortex is found with a ball-tipped probe. The medial, lateral, inferior, superior, and anterior walls are carefully palpated to confirm intraosseous position. A screw measurement is then taken based upon the depth of the ball-tipped probe into the $\mathrm{C} 7$ vertebral body. The pedicle tract is then tapped and probed again for any new breaches. The pedicle screw is then placed. The remainder of the subaxial cervical lateral mass screws can then be placed. Antero-posterior and lateral fluoroscopic images are taken intraoperatively to assess hardware position (see Figure 2) [13-14].

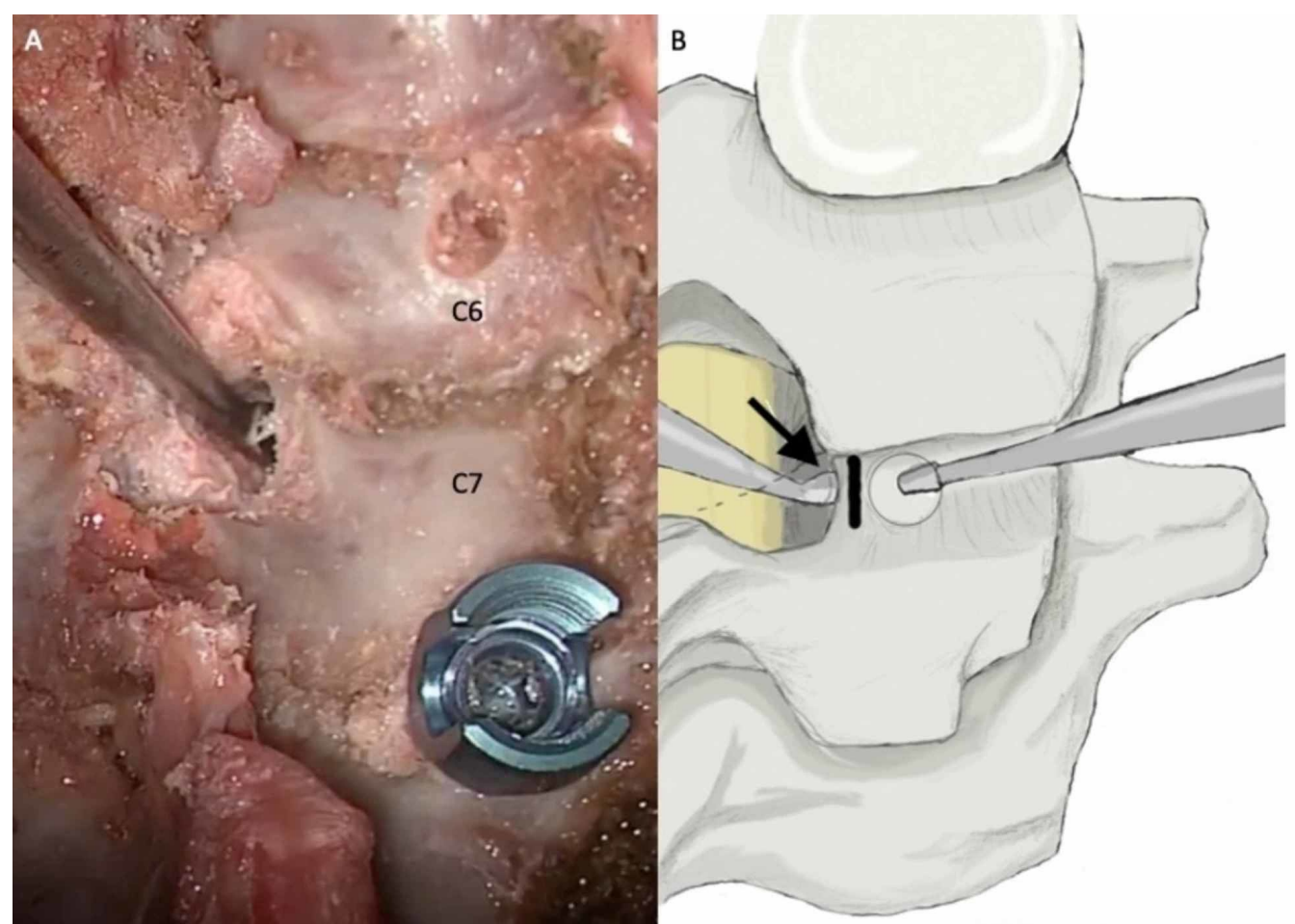

\section{FIGURE 1: Identification of medial C7 pedicle border.}

(A) Intraoperative photo of medial C7 pedicle palpation after laminotomy and (B) artist's rendering of the 66-7 level during posterior instrumented cervicothoracic fusion. A curette is placed on the medial border of the $\mathrm{C} 7$ pedicle after a small superior laminotomy is performed (black arrow). The black line indicates the projected medial pedicle boundary, which is used for pedicle screw placement trajectory. 


\section{Cureus}

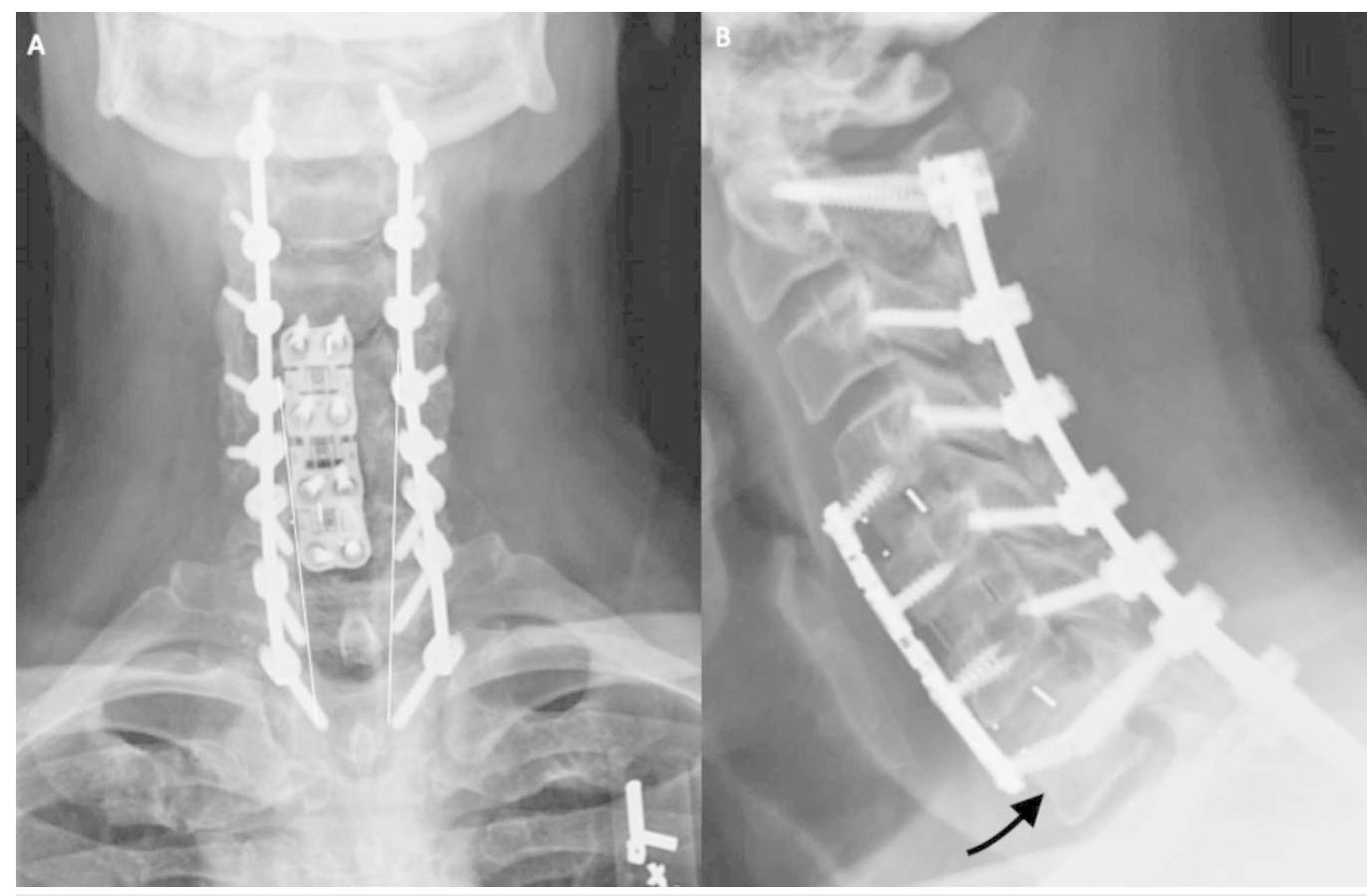

FIGURE 2: Radiograph breach assessment.

(A) The harmonious line conceived by linking the pedicle boundaries at adjacent levels (white lines) allows for assessment of medial and lateral breaches on plain films as previously described by Kim et al. on plain radiographs. (B) Lateral radiographs allow for assessment of anterior breaches by locating the tip of the pedicle screw in relation to the anterior cortex (black arrow).

\section{Results}

Forty-eight patients were identified that underwent posterior cervical or cervicothoracic fusion by the senior author from 2013 to 2018. Of these patients, 20 met the inclusion criteria.

Tables 1-2 contain the pertinent demographics and measured variables for the study. A total of $40 \mathrm{C} 7$ pedicle screw placements in these 20 patients were attempted, with 36 successful (90\%). Six patients in our series had constructs ending at $\mathrm{C} 7$. There were no observed intraoperative complications or revisions related to screw placement. There were four screw attempts that were not successful. Three were due to screw crowding secondary to structural deformity of the cervicothoracic junction. One screw attempt had a superior breach into the C6-7 foramen, and thus was left out (Patient \#17). A lateral mass screw at C7 was placed instead in this instance. There were no neurologic consequences from the initial breach.

\begin{tabular}{|c|c|c|c|c|}
\hline Patient & Age & Procedure & $\begin{array}{l}\text { Right } \\
\text { pedicle } \\
\text { screw size } \\
(\mathrm{mm})\end{array}$ & $\begin{array}{l}\text { Left pedicle } \\
\text { screw size } \\
(\mathrm{mm})\end{array}$ \\
\hline 1 & 41 & $\begin{array}{l}\text { C4-C5 decompressive laminectomy; C2-C7 posterior instrumented } \\
\text { arthrodesis }\end{array}$ & $4.35 \times 25$ & $4.35 \times 25$ \\
\hline 2 & 53 & C3-C7 decompressive laminectomy; C2-T2 instrumented fusion & $4.0 \times 26$ & $4.0 \times 26$ \\
\hline 3 & 53 & $\begin{array}{l}\text { C2-C7 decompressive laminectomy; posterior instrumented cervical } \\
\text { arthrodesis }\end{array}$ & $4.35 \times 20$ & $4.35 \times 25$ \\
\hline
\end{tabular}




\section{Cureus}

\begin{tabular}{|c|c|c|c|c|}
\hline 4 & 55 & $\begin{array}{l}\text { Bilateral C4-C5 foraminotomy; Left C7-T1 foraminotomy; Left T1-T2 } \\
\text { foraminotomy; C2-T2 instrumented fusion }\end{array}$ & $4.0 \times 26$ & $4.0 \times 26$ \\
\hline 5 & 55 & $\begin{array}{l}\text { C3-C6 decompressive laminectomy; C2-T1 posterior instrumented } \\
\text { fusion }\end{array}$ & $4.0 \times 24$ & $4.0 \times 26$ \\
\hline 6 & 59 & C3-4 decompressive laminectomy; C2-T2 instrumented fusion & $4.0 \times 26$ & $\begin{array}{l}\text { (left out due to } \\
\text { crowding) }\end{array}$ \\
\hline 7 & 59 & $\begin{array}{l}\text { C5-C6 decompressive laminectomy; Right C6 foraminotomy; C4-C7 } \\
\text { instrumented fusion }\end{array}$ & $4.0 \times 24$ & $4.0 \times 24$ \\
\hline 8 & 60 & Right C6-7 revision foraminotomy; C2-T2 instrumented fusion & $4.5 \times 25$ & $4.5 \times 25$ \\
\hline 9 & 61 & $\begin{array}{l}\text { Posterior C7 decompressive laminectomy; C5-T1 posterior } \\
\text { instrumented fusion }\end{array}$ & $4.0 \times 24$ & $4.0 \times 24$ \\
\hline 10 & 62 & $\begin{array}{l}\text { C5-C7 decompressive laminectomy; Right C6 and C7 foraminotomy; } \\
\text { Bilateral C8 foraminotomy and resection of synovial cysts; C2-T2 } \\
\text { instrumented fusion }\end{array}$ & $4.0 \times 26$ & $4.0 \times 26$ \\
\hline 11 & 64 & C3-C6 decompressive laminectomy; C2-T3 instrumented fusion & $4.0 \times 26$ & $\begin{array}{l}\text { (left out due to } \\
\text { crowding) }\end{array}$ \\
\hline 12 & 65 & C3-C7 decompressive laminectomy; C2-T2 instrumented fusion & $4.0 \times 26$ & $4.0 \times 26$ \\
\hline 13 & 66 & Bilateral C8 foraminotomy; C7-T1 instrumented fusion & $4.0 \times 24$ & $4.0 \times 24$ \\
\hline 14 & 67 & $\begin{array}{l}\text { Anterior C4, C5, and C6 corpectomy; C3-C7 instrumented fusion; } \\
\text { posterior C2-T3 instrumented fusion }\end{array}$ & $\begin{array}{l}\text { (left out due } \\
\text { to crowding) }\end{array}$ & $3.5 \times 20$ \\
\hline 15 & 69 & C3-C6 decompressive laminectomy; C2-T2 instrumented fusion & $4.0 \times 26$ & $4.0 \times 26$ \\
\hline 16 & 70 & $\begin{array}{l}\text { Left C7 foraminotomy; C6-C7 laminectomy; C4-C7 instrumented } \\
\text { fusion }\end{array}$ & $4.35 \times 25$ & $4.35 \times 25$ \\
\hline 17 & 70 & $\begin{array}{l}\text { C5, C6, and C7 decompressive laminectomies; C2-T2 posterior } \\
\text { instrumented fusion }\end{array}$ & $4.0 \times 28$ & $\begin{array}{l}\text { (lateral mass } \\
\text { screw placed due } \\
\text { to break) }\end{array}$ \\
\hline 18 & 71 & $\mathrm{C} 2-\mathrm{C} 7$ decompressive laminectomy; C2-C7 instrumented fusion & $4.35 \times 30$ & $4.35 \times 30$ \\
\hline 19 & 73 & C5 Laminectomy; C3-C7 instrumented fusion & $4.0 \times 28$ & $4.0 \times 28$ \\
\hline 20 & 75 & C7 decompressive laminectomy; C3-T3 instrumented fusion & $4.35 \times 25$ & $4.35 \times 25$ \\
\hline
\end{tabular}

\section{TABLE 1: Patient demographics and C7 pedicle screw dimensions.}

$\mathrm{mm}$, millimeters. 


\section{Cureus}

\begin{tabular}{|c|c|c|c|c|c|c|}
\hline Patient & $\begin{array}{l}\text { C7 screw } \\
\text { intraoperative } \\
\text { repositioning required }\end{array}$ & $\begin{array}{l}\text { C7 at } \\
\text { bottom of } \\
\text { construct }\end{array}$ & $\begin{array}{l}\text { Postoperative } \\
\text { CT/XR }\end{array}$ & $\begin{array}{l}\text { Breaches } \\
\text { observed }\end{array}$ & $\begin{array}{l}\text { Postoperative } \\
\text { neurologic } \\
\text { complications }\end{array}$ & $\begin{array}{l}\text { Follow-up } \\
\text { to date } \\
\text { (months) }\end{array}$ \\
\hline 1 & No & Yes & XR & None & None & 25 \\
\hline 2 & No & No & $\mathrm{XR}, \mathrm{CT}$ & None & None & 13 \\
\hline 3 & No & Yes & XR, CT & $\begin{array}{l}<2 \mathrm{~mm} \text { (L- } \\
\text { anterior) }\end{array}$ & None & 4 \\
\hline 4 & No & No & $\mathrm{CT}, \mathrm{XR}$ & $\begin{array}{l}<2 \mathrm{~mm}(\mathrm{R}- \\
\text { medial) }\end{array}$ & None & 13 \\
\hline 5 & No & No & $\mathrm{XR}$ & None & None & 1 \\
\hline 6 & No & No & $\mathrm{XR}, \mathrm{CT}$ & None & None & 2 \\
\hline 7 & No & Yes & $X R$ & None & None & 12 \\
\hline 8 & No & No & $\mathrm{XR}$ & None & None & 6 \\
\hline 9 & No & No & XR, CT & None & None & 13 \\
\hline 10 & No & No & $\mathrm{XR}, \mathrm{CT}$ & None & None & 11 \\
\hline 11 & No & No & XR, CT & None & None & 12 \\
\hline 12 & No & No & XR & None & None & 25 \\
\hline 13 & No & No & XR & None & None & 12 \\
\hline 14 & No & No & XR & None & None & 2 \\
\hline 15 & No & No & $\mathrm{XR}, \mathrm{CT}$ & None & L C5 palsy & 2 \\
\hline 16 & No & Yes & $\mathrm{XR}, \mathrm{CT}$ & $\begin{array}{l}<2 \mathrm{~mm}(\mathrm{R}- \\
\text { anterior, L- } \\
\text { lateral) }\end{array}$ & None & 16 \\
\hline 17 & No & No & $\mathrm{XR}, \mathrm{CT}$ & None & None & 9 \\
\hline 18 & No & Yes & XR & None & R C5 palsy & 6 \\
\hline 19 & No & Yes & $\mathrm{CT}, \mathrm{XR}$ & None & None & 3 \\
\hline 20 & No & No & XR, CT & None & None & 8 \\
\hline
\end{tabular}

TABLE 2: Patient variables related to $C 7$ pedicle screw placement and assessment.

$\mathrm{CT}$, computed tomography; XR, X-ray; L, left; R, right.

There were no neurologic complications related to screw placement. Two patients had delayed postoperative C5 palsy not related to instrumentation. All patients received intraoperative Xray to confirm intraosseous position before procedure end. Eleven patients had a postoperative 
CT performed within the complete follow-up period. Eight were performed according to the treating surgeon's standard practice of 8-12 month follow up to assess fusion. Three were performed within the same postoperative hospitalization period. Two of these were performed on the patients with C5 palsies, and one was performed on a patient with beyond expected postoperative incisional pain. None of these three patients had breaches on CT.

The overall accuracy rate for screw placement (Grade 0) was 89\% (32/36). There were three patients with four screws with identifiable minor $(<2 \mathrm{~mm})$ breaches on CT. Patient \#3 had slight bicortical purchase of the left screw. Patient $\# 4$ had a small medial breach of the right screw in the proximal portion of the pedicle. Patient \#16 had mild anterior bicortical purchase of the right screw, and a small lateral breach on the left screw. None of these patients had neurologic symptoms or complications related to these minor breaches. Fusion rates for patients with at least eight months of follow up was $100 \%(n=12)$. Eight patients received CT evaluation and four received X-ray evaluation of the construct.

\section{Discussion}

Pedicle screw insertion at C7 is a well-published technique to enhance the biomechanical stability of cervical and cervicothoracic constructs [4, 15-16]. There are numerous methods of pedicle screw insertion. The CT-guided navigation is a commonly used method for patientspecific instrumentation with excellent instrumentation accuracy [6]. The significance of radiation exposure to the patient and practitioner using this approach has been a widely debated topic $[8,17]$. Other patient-specific techniques have utilized three-dimensional printing of guide tubes to increase the accuracy of pedicle screw placement at $\mathrm{C} 7$ as well as rest of the subaxial cervical spine with good results [18]. This requires labor intensive and time intensive conversion of patient-specific digital imaging files to stereolithography files for printing, making this technique less ideal for emergent cases that do not have substantial time for preoperative planning. Material costs for this method of screw placement are also significant. Anatomical techniques using only posterior element landmarks have been utilized to decrease intraoperative fluoroscopy and radiation exposure [4, 16, 19]. Breach rates using these methods have been reported as high as $13 \%$, however, with a very low rate of neurologic complications [5]. At our institution, we prefer to utilize a small laminotomy as a window to directly palpate the pedicle for ascertainment of the medial, superior, and inferior boundaries. This allows for direct visualization of the pedicle screw insertion trajectory. An advantage of this technique is choosing a pedicle entry point that will allow for pedicle access as well as the ability to properly interact with the superior C6 lateral mass screw head and the inferior T1 pedicle screw head during rod placement across the cervicothoracic junction.

In our study, we did not observe any complications relating to pedicle screw placement. For the 11 patients with postoperative CT, three patients exhibited minor (Grade 1) breaches. Two were bicortically placed anteriorly, one lateral, and one medial (four screws total). For patients with a postoperative plain film, there were no observed breaches based on parameters of radiographic evaluation [12]. Our accuracy rate for screw placement (Grade 0) was 89\% (32/36). This rate is similar to other reported studies using freehand technique [3, 4, 9-11, 14].

There were 12 patients in our series that had at least eight months of follow up with imaging to assess fusion. All patients met the criteria for construct fusion. This was not compared with a control, so it is difficult to determine whether there is a significant difference in fusion rates for our cohort with $\mathrm{C} 7$ pedicle screws compared with other construct designs. Posterior cervical constructs have a high fusion rate in general as reported in the existing literature [20]. As the primary outcomes for pedicle screw placement in this study were safety and accuracy using a freehand technique, this secondary outcome measure was not investigated further.

There are several limitations to our study. The first is the retrospective method for data 
acquisition. The second is the heterogenous nature of determining breach rates with CT and plain film. It is likely that very minor breaches (Grade 1) were not able to be identified on plain film evaluation that may have been observed on CT due to resolution differences between the two modalities, possibly creating false negative results. With respect to clinical significance, the Grade 1 breaches observed on CT in our patient cohort did not contact neurovascular structures or produce any patient symptoms. The consequences of minor breaches in pedicle screw placement have been investigated and established in previous publications [5, 14, 19]. As there were no neurologic complications relating to screw placement in our series, the possibility of missed minor breaches did not change patient safety factors or outcomes in this study, indicating clinical insignificance if present.

\section{Conclusions}

Freehand pedicle screw placement at C7 is a safe and viable option for fixation of posterior cervical constructs at the cervicothoracic junction. In the widespread advent of new technologies for instrumentation such as robotic systems and optical navigation, the surgical anatomy of proper $\mathrm{C} 7$ pedicle screw placement remains an important and relevant concept to ensure accurate instrumentation independent of technologic availability.

\section{Additional Information \\ Disclosures}

Human subjects: Consent was obtained by all participants in this study. Mayo Clinic IRB issued approval 18-003951-03. This study was approved after review by the IRB. Animal subjects: All authors have confirmed that this study did not involve animal subjects or tissue. Conflicts of interest: In compliance with the ICMJE uniform disclosure form, all authors declare the following: Payment/services info: All authors have declared that no financial support was received from any organization for the submitted work. Financial relationships: All authors have declared that they have no financial relationships at present or within the previous three years with any organizations that might have an interest in the submitted work. Other relationships: All authors have declared that there are no other relationships or activities that could appear to have influenced the submitted work.

\section{References}

1. Joaquim AF, Mudo ML, Tan LA, Riew KD: Posterior subaxial cervical spine screw fixation: a review of techniques. Global Spine J. 2018, 8:751-760. 10.1177/2192568218759940

2. Hostin RA, Wu C, Perra JH, Polly DW, Akesen B, Wroblewski JM: A biomechanical evaluation of three revision screw strategies for failed lateral mass fixation. Spine. 2008, 33:2415-2421.

3. Ludwig SC, Kramer DL, Balderston RA, Vaccaro AR, Foley KF, Albert TJ: Placement of pedicle screws in the human cadaveric cervical spine: comparative accuracy of three techniques. Spine. 2000, 25:1655-1667.

4. Reinhold M, Magerl F, Rieger M, Blauth M: Cervical pedicle screw placement: feasibility and accuracy of two new insertion techniques based on morphometric data. Eur Spine J. 2007, 16:47-56. 10.1007/s00586-006-0104-1

5. Neo M, Sakamoto T, Fujibayashi S, Nakamura T: The clinical risk of vertebral artery injury from cervical pedicle screws inserted in degenerative vertebrae. Spine. 2005, 30:2800-2805.

6. Ishikawa Y, Kanemura T, Yoshida G, et al.: Intraoperative, full-rotation, three-dimensional image (O-arm)-based navigation system for cervical pedicle screw insertion. J Neurosurg Spine. 2011, 15:472-478. 10.3171/2011.6.Spine10809

7. Lee DH, Lee SW, Kang SJ, et al.: Optimal entry points and trajectories for cervical pedicle screw placement into subaxial cervical vertebrae. Eur Spine J. 2011, 20:905-911. 10.1007/s00586-010-1655-8

8. Urbanski W, Jurasz W, Wolanczyk M, et al.: Increased radiation but no benefits in pedicle screw accuracy with navigation versus a freehand technique in scoliosis surgery. Clin Orthop 
Relat Res. 2018, 476:1020-1027. 10.1007/s11999.0000000000000204

9. Celikoglu E, Borekci A, Ramazanoglu AF, Cecen DA, Karakoc A, Bektasoglu PK: Posterior transpedicular screw fixation of subaxial vertebrae: accuracy rates and safety of minilaminotomy technique. Asian J Neurosurg. 2019, 14:58-62. 10.4103/ajns.AJNS_178_17

10. Lee GW, Kim HJ, Yeom JS, et al.: Feasibility study of free-hand technique for pedicle screw insertion at C7 without fluoroscopy-guidance. Asian Spine J. 2016, 10:38-45.

10.4184/asj.2016.10.1.38

11. Wang Y, Xie J, Yang Z, et al.: Computed tomography assessment of lateral pedicle wall perforation by free-hand subaxial cervical pedicle screw placement. Arch Orthop Trauma Surg. 2013, 133:901-909.

12. Lee SH, Kim KT, Suk KS, et al.: Assessment of pedicle perforation by the cervical pedicle screw placement using plain radiographs: a comparison with computed tomography. Spine. 2012, 37:280-285.

13. Lehman RA, Sasso RC, Helgeson MD, et al.: Accuracy of intraoperative plain radiographs to detect violations of intralaminar screws placed into the $\mathrm{C} 2$ vertebrae: a reliability study. Spine. 2007, 32:3036-3040.

14. Kim YJ, Lenke LG, Cheh G, Riew KD: Evaluation of pedicle screw placement in the deformed spine using intraoperative plain radiographs: a comparison with computerized tomography. Spine. 2005, 30:2084-2088.

15. Reinhold M, Bach C, Audige L, et al.: Comparison of two novel fluoroscopy-based stereotactic methods for cervical pedicle screw placement and review of the literature. Eur Spine J. 2008, 17:564-575. 10.1007/s00586-008-0584-2

16. Pelton MA, Schwartz J, Singh K: Subaxial cervical and cervicothoracic fixation techniques-indications, techniques, and outcomes. Orthop Clin North Am. 2012, 43:19-28.

17. Nottmeier EW, Pirris SM, Edwards S, Kimes S, Bowman C, Nelson KL: Operating room radiation exposure in cone beam computed tomography-based, image-guided spinal surgery: clinical article. J Neurosurg Spine. 2013, 19:226-231. 10.3171/2013.4.Spine12719

18. Moser M, Farshad M, Farshad-Amacker NA, Betz M, Spirig JM: Accuracy of patient-specific template-guided versus freehand cervical pedicle screw placement from C2-C7: a randomized cadaveric study. World Neurosurg. 2019, 10.1016/j.wneu.2019.02.152

19. Oshina M, Horii C, Hirai S, et al.: Comparison of freehand sagittal trajectories for inserting pedicle screws between C7 and T5. Clin Spine Surg. 2018, 31:357. $10.1097 /$ bsd.0000000000000663

20. Xia Y, Xu R, Kosztowski TA, et al.: Reoperation for proximal adjacent segment pathology in posterior cervical fusion constructs that fuse to C2 vs C3. Neurosurgery. 2019, 10.1093/neuros/nyz019 